\title{
Mast cells in relation to Helicobacter pylori and chronic active gastritis
}

\author{
$\mathrm{KC} \mathrm{Geetika}^{1}$, KC Shiva Raj ${ }^{2}$ \\ ${ }^{I}$ Department of Pathology, KIST medical college, Imadol, Lalitpur, Nepal. \\ ${ }^{2}$ Department of Pathology, GRP Polyclinic Pvt. Ltd. Kathmandu, Nepal
}

\author{
Keywords: \\ Activity, \\ Grading; Peptic ulcer; \\ Giemsa; \\ Helicobacter; \\ Gastritis.
}

\begin{abstract}
Background: Gastritis is commonly reported using several parameters such as infiltration by neutrophils, lymphocytes, intestinal metaplasia, atrophy and Helicobacter pylori. In recent years, mast cells are also suggested in several studies to play central role in development of gastritis. This study tried to look at the relation between the mast cell count and infiltration by neutrophils and Helicobacter pylori.

Materials and methods: This is a retrospective study which includes endoscopic gastric biopsies received at the histopathology department of GRP polyclinic that have been diagnosed as chronic gastritis. Clinical information regarding associated gastrointestinal symptoms and conditions were obtained from the medical database. Patients taking antibiotics, proton-pump inhibitors, H2- antagonists, nonsteroidal anti-inflammatory drugs or corticosteroids were excluded from the study. Also excluded are patients with dysplasia or carcinoma. Sections were then stained by H\&E and Giemsa for the evaluation of $\mathrm{H}$ pylori infection and inflammation. These sections were examined by two pathologists. Mast cells were counted in 1000 epithelial cells in 40x. Three different counts were performed by each pathologists and an average score was taken for every case.
\end{abstract}

Result: A total of 534 cases were included in the study. Mast cells were detected in all the cases. However, mast cells were seen mostly in mild grade $321(60 \%)$. Ninty-eight percent of our cases showed H.pylori positivity and $385(72 \%)$ of cases had active gastritis. A positive correlation was found between mast cells density and infiltration by neutrophils as well as Helicobacter pylori infection with significant $\mathrm{P}$ value of 0.0001 in each.

Conclusion: Mast cells are seen in a significant number of biopsies with gastritis showing positive correlation with neutrophilic infiltration and Helicobacter pylori infection.

\section{INTRODUCTION}

Gastritis is common finding in most clinical settings. Helicobacter pylori is a known etiological agent causing gastritis, peptic ulcer disease and also gastric carcinoma in long term. ${ }^{1}$ Well known microscopic finding in the gastric mucosa with Helicobacter pylori is, neutrophils (indicating activity) in lamina propria and intraepithelium. ${ }^{2}$ Apart from these findings, mast cells are also seen to be related to the

\section{Correspondence:}

Dr Geetika KC, MBBS, MD

Department of Pathology,

KIST medical college, Imadol, Lalitpur, Nepal.

email:geetikakc@hotmail.com
Helicobacter pylori (H. pylori) gastritis. These cells are supportive tissue of skin, gastrointestinal lining, the serosal lining of the peritoneal cavity and around blood vessels. These granulated cells have been well established to have a central role in type I hypersensitivity reaction. However, they are also implicated in mucus secretion, smooth muscle contraction, other hypersensitivity reactions, wound healing and several other diseases such as inflammatory bowel disease and autoimmune diseases. ${ }^{3,4}$

Gastritis is most commonly reported using modified Sydney system which includes etiology (if known), topography and morphology ${ }^{5,6}$ Helicobacter pylori and neutrophils are 
reported as part of it. In recent years, several studies show mast cells as an important effector cell in the pathogenesis of gastritis and more so in Helicobacter pylori associated peptic ulcer. ${ }^{3,4}$ Mast cell is so far not including in the routine reporting systems of gastritis.

This study tries to look at the relationship between mast cells and several specific factors of the modified Sydney reporting system.

\section{MATERIAL AND METHODS}

This is a retrospective study which includes endoscopic gastric biopsies received at the histopathology department of GRP clinic that have been diagnosed as chronic gastritis from January 2015 to March 2015. Clinical information

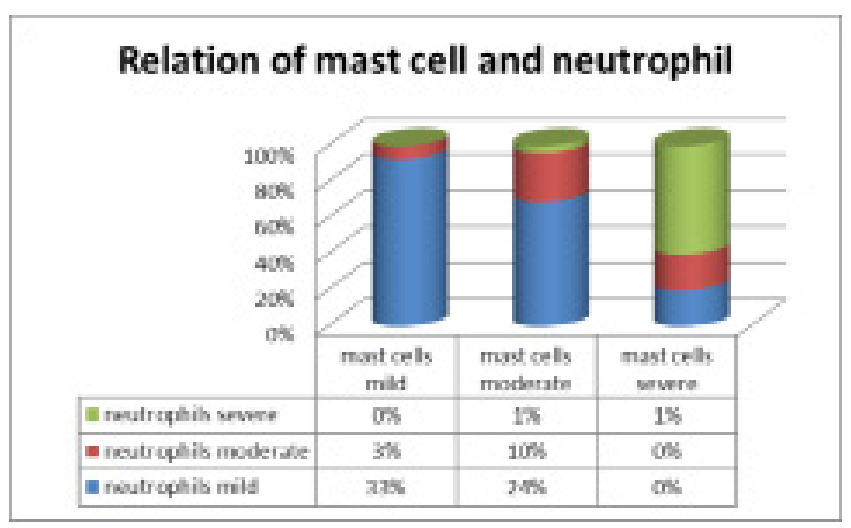

Figure 1. Distribution of mast cell (yaxis) in relation to the activity ( $x$-axis) in the gastric mucosa $(n=534)$.

regarding associated gastrointestinal symptoms and conditions were obtained from the medical database. Patients taking antibiotics, proton-pump inhibitors, $\mathrm{H} 2$ - antagonists, nonsteroidal anti-inflammatory drugs or corticosteroids were excluded from the study. Also excluded are patients with dysplasia or carcinoma. All patients fulfilling the criteria signed an informed consent form. For each patient, biopsy specimens were fixed in $10 \%$ buffered formalin, processed, embedded in paraffin and cut into sequential $4 \mathrm{~mm}$ sections. Sections were then stained by H\&E and Giemsa for the evaluation of $\mathrm{H}$ pylori infection and inflammation. These sections were examined by two pathologists. Helicobacter

Table 1:Distribution of grade of modified Sydney System parameters

\begin{tabular}{lccccc}
\hline \multicolumn{1}{c}{ Parameter } & Mild & Moderate & Severe & Nil & Total \\
\hline Helicobacter pylori & $136(25 \%)$ & $303(57 \%)$ & $83(16 \%)$ & $12(2 \%)$ & \\
\hline Intestinal metaplasia & $49(9 \%)$ & $12(2 \%)$ & $1(0 \%)$ & $472(88 \%)$ & \\
Atrophy & $299(56 \%)$ & $74(14 \%)$ & $18(3 \%)$ & $143(27 \%)$ & 534 \\
Lymphocytic infiltration & $177(33 \%)$ & $23(4 \%)$ & $5(1 \%)$ & $329(61 \%)$ & \\
Neutrophils & $306(57 \%)$ & $66(12 \%)$ & $13(2 \%)$ & $149(28 \%)$ & \\
& & & & &
\end{tabular}

pylori was diagnosed on histological basis. Mast cells were counted in 1000 epithelial cells in 10 fields of 40x, and graded as mild ( $\leq 15 / 10 \mathrm{hpf})$, moderate (16-30/10 hpf) and severe ( $\geq 31 / 10 \mathrm{hpf})$. Three different counts were performed by each pathologists and an average score was taken for every case.

\section{RESULTS}

We had a total of 534 cases over a period of 2 months.

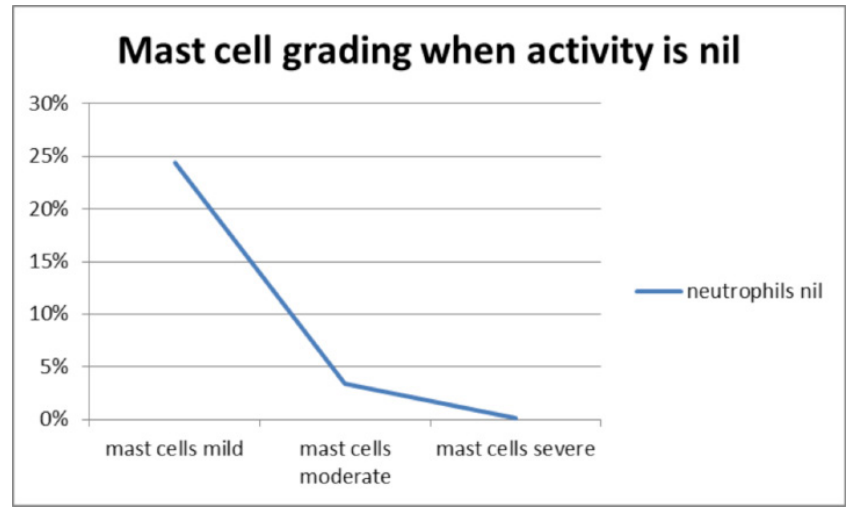

Figure 2 : Distribution of mast cells (y-axis) and its relation to gastric mucosa with no neutrophilic activity ( $x$-axis) $(n=534)$.

Out of the 534 cases lymphocytes, neutrophils, intestinal metaplasia, atrophy and mast cells were graded into nil, mild, moderate and severe. Table 1 shows the distribution of the grade of the five modified Sydney system parameters.

Helicobacter pylori were seen in $522(98 \%)$ of cases with moderate being $57 \%$. Intestinal metaplasia was seen in 61 $(11 \%)$ of cases, atrophy was seen in 391 (73\%) of cases and chronic inflammatory cells in $205(39 \%)$ of cases. Activity was seen in $385(72 \%)$ of cases with mild grade being predominant.

We found mast cells density to be mild in $321(60 \%)$ of cases followed by 207 (39\%) of cases and severe in 6 $(1 \%)$ of cases as seen in Table 2 . The severity of mast cell infiltration and neutrophilic infiltration positively correlated with a significant p-value of 0.0001 as seen in Fig. 1. Cases with no activity showed mostly mild (24\%) mast cell infiltration (Fig. 2). In our study, mast cells were seen to be in moderate $(13 \%)$ to severe $(1 \%)$ amount with severe H.pylori infiltration. Mast cell count was predominantly mild with cases of mild to moderate H.pylori infiltration ( $21 \%$ and $31 \%$ respectively). Mast cell and H.pylori showed

Table 2: Mast cell density in $x 400$ per 10 hdf

\begin{tabular}{ccc}
\hline Mast cells & Cells/10 HPF & Percentage \\
\hline$\leq 15$ & 321 & $60 \%$ \\
$16-30$ & 207 & $39 \%$ \\
$\geq 31$ & 6 & $1 \%$ \\
Total & 534 & $100 \%$
\end{tabular}




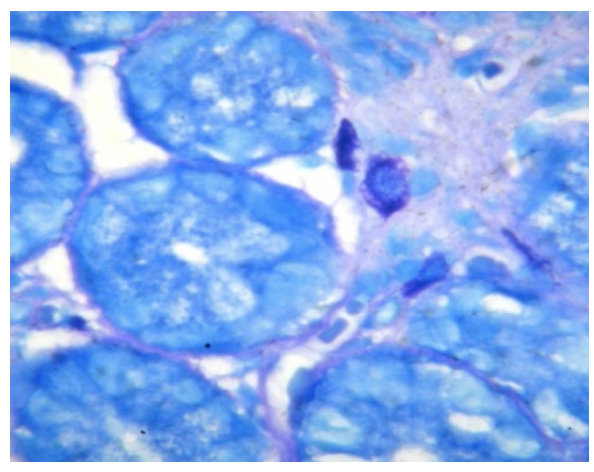

Figure 1: Photomicrograph showing mast cells in the lamina propria of gastric mucosa (Giemsa stain, X1000).

significant $\mathrm{p}$ value of 0.0001 (Fig. 3).

\section{DISCUSSION}

Out of the cells induced by Helicobacter pylori, mast cells have been of major interest in recent years. It is thought to have a central role in the morphology of acid peptic diseases. In our study we found $98 \%$ of cases to have $\mathrm{H}$. pylori infection using histopathological evaluation with Giemsa stain. Moderate grade of severity was the most common presentation accounting to $57 \%$ of cases. In the study done by Suzana MK et $\mathrm{al}^{7} \mathrm{H}$. pylori infection was seen in $23.38 \%$ of cases which was lower than our study. Similar to our study they also had a peak in the moderate grade.

We graded mast cells into mild ( $\leq 15 / 10 \mathrm{hpf})$, moderate (16 to $30 / 10 \mathrm{hpf})$ and severe ( $\geq 31 / 10 \mathrm{hpf})$ in all of our cases. We used Giemsa stain to identify the mast cells. Though staining by anti-tryptase antibody using immunohistochemical methods is more specific. it is expensive alternative for our set up $321(60 \%)$ of the cases had mild mast cell infiltration followed by 207 (39\%) of cases having moderate infiltration. Mast cell grading varies in different studies and no uniformity was found. ${ }^{4,7-9}$ Hence our study graded into three tiered system for comparison between different component of the Sydney reporting system.

As a control the cases with nil activity had only $24 \%$ of mild mast cell infiltration. Mast cells have been noted in all the biopsies and shows positive correlation with activity $(\mathrm{P}<$ $0.0001)$ and H. pylori $(\mathrm{P}<0.0001)$. These cells were seen to be in moderate $(13 \%)$ to severe $(1 \%)$ amount with severe H.pylori infiltration in this study.

In a study done by Nakajima $\mathrm{S}$ et $\mathrm{al},{ }^{4}$ fold increase in mast cells were seen in gastritis cases than normal. They noted that mast cells were increased even more, by 5-9 folds, in $\mathrm{H}$. pylori positive chronic gastritis and peptic ulcer diseases of antrum. In our study, mast cells have been noted in all the biopsies and shows positive correlation with activity ( $\mathrm{P}$ value is less than 0.0001$)$ and $\mathrm{H}$. pylori $(\mathrm{P}<0.0001)$.

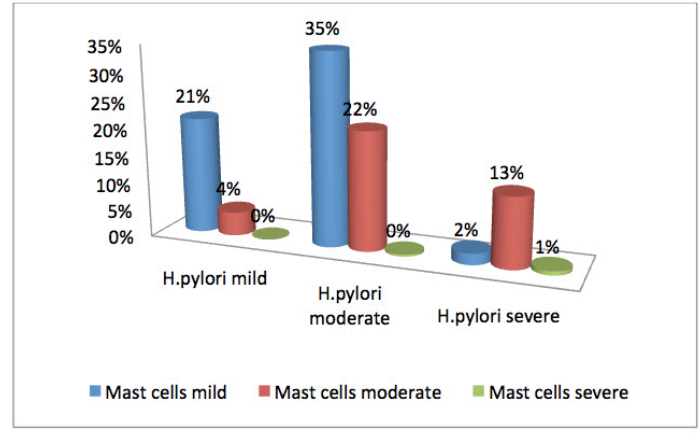

Figure 3: Distribution of mast cells (y-axis) in relation to Helicobacter pylori (y-axis).

Mast cells have been known to be a main effector in type 1 hypersensitivity reaction however they are also involved in inflammation, mucus secretion, smooth muscle contraction, other hypersensitivity reactions and in wound healing. ${ }^{3,4}$ Two subtypes of mast cells have been reported- one is connective tissue type and another one is mucosal-type. The later type is common in the gastrointestinal tract. Both of these subtypes contain tryptase but the mucosal type contains both tryptase and chymase. ${ }^{4,10}$ Mast cells contain preformed (histamine, chymase, tryptase, acid hydrolases, heparin and chondroitin sulfate) and de novo synthesized (leukotrienes, prostaglandin $\mathrm{D}_{2}$, Platelet-activating factor, TNF, IL-1, IL-4, IL-6 and many others) mediators. ${ }^{12}$ Triggers for the release of these mediators are $\mathrm{Fc}$ portion of IgE, complements (C5a,C3a), toll like receptor activation, other chemokines (e.g IL-8), drugs (e.g. codeine) and physical stimuli (e.g. heat, cold). ${ }^{12}$ Once the mediators are released immediate reaction includes vasodilation, vascular leakage and smooth muscle spasm. Late reactions include leukocytes infiltrations (neutrophil, eosinophil and plasma cells), epithelial damage and bronchospasm. ${ }^{12}$ Apart from these it is also postulated that mast cells promote vascular endothelial growth factor (VEGF) production by secretion of tyrptase which causes cyclooxygenase pathway activation and via prostaglandin E2 causes increased VEGF production. ${ }^{13}$ Also noted is an immunosuppressive effect of mast cells via production of IL-10, proteases and certain chemokines. ${ }^{13}$

Helicobacter pylori has been proven to be associated with gastritis and ulcerations. Its discovery has been reported as a revolutionary in treatment for gastritis. Helicobacter pylori infected stomach causes production of IL-6 (growth factor for mast cells) and IL-3 and 4 (chemotactic factors for mast cells). In addition, the HP-NAP and VacA can cause direct production of mast cell cytokines and also cause its migration. ${ }^{714}$ It is also noted that in the epithelium associated with high density of mast cells there is decreased expression of anti-apoptotic proteins (Bcl-2 and $\mathrm{BCl}-\mathrm{X})$ and increased expression of proapoptotic (Bax and caspase 3) proteins. $^{7}$ 
The mast cell has been suggested to be in the epicenter of the gastritis pathogenesis leading to inflammation, ulcerations and fibrosis. The treatment aim at Helicobacter pylori has led to significant decrease in the mucosal and epithelial mast cell density. ${ }^{4}$

The rest of the findings in our study showed intestinal metaplasia in $11 \%$ of cases with $9 \%$ in the mild category, $73 \%$ of cases with atrophy and among them $56 \%$ were of mild degree. Similarly, chronic inflammation without activity was seen in $13 \%$ of cases and among them mild was seen in $12 \%$ of cases. Activity was seen in $72 \%$ of cases and mild degree accounted to $57 \%$ of cases. In another study, 10 similar to our study, intestinal metaplasia was seen in $16.23 \%$ of cases and was maximum in the mild grade. In their study, atrophy was seen in only $15 \%$ of cases which was lower than our study. Activity was seen in $73.38 \%$ of cases, ${ }^{10}$ which was similar to our study and was maximum in mild grade $(36 \%)$. In their study, chronic gastritis without activity was seen in $26.6 \%$ of cases, which was higher than ours. $^{10}$

\section{CONCLUSION}

Our study shows positive correlation between mast cells count with activity and H.pylori infection. However, this study lacks resources for more specific tests and needs further evolution to come to definite conclusions.

\section{REFERENCES}

1. Correa P. Helicobacter pylori and gastric carcinogenesis. Am J Surg Pathol. 1995;19:S37-S43 Crossref

2. Dixon MF, Genta RM, Yardley JH, et al. Classification and grading of gastritis: the updated Sydney system. Am J Surg Pathol. 1996;20:1161-81. Crossref

3. Bachelet I, Levi-Schaffer F, Mekori YA. Mast cell: not only in allergy. Immunol Allergy Clin North Am. 2006;26:407-25. Crossref

4. Nakajima S, Krishnan B, Ota $\mathrm{H}$ et al. Mast cell involvement in gastritis with or without Helicobacter pylori infection. Gastroenterol 1997;113:746-54. Crossref

5. Dixon MF, Genta RM, Yardley JH, Correa P. Classification and grading of gastritis: the updated Sydney system, International
Workshop on the Histopathology of Gastritis, Houston 1994. Am J Surg Pathol 1996; 20:1161-81. Crossref

6. El-Zimaity HMT, Riddell RH, Abudayyeh S, Opekum AR, Graham DY. Gastric atrophy diagnostic accuracy: comparison of OLGA with Baylor system. Lab Invest 2009; 89(Suppl 1):128A.

7. Nakajima S, Krishnan B, Ota $\mathrm{H}$ et al. Mast cell involvement in gastritis with or without Helicobacter pylori infection. Gastroenterol 1997;113:746-54. Crossref

8. Hofman V, Lassalle S, Selva E et al. Involvement of mast cells in gastritis caused by Helicobacter pylori: a potential role in epithelial cell apoptosis. J Clin Pathol 2007;60:600-7. Crossref

9. KC SR, Amatya GL. Association of mast cells with helicobacter pylori infection in the antral mucosa. Journal of Pathology of Nepal 2011;1:34 -7. Crossref

10. Suzana MK, Skender T, Emine DD et al. Helicobacter pylori gastritis updated Sydney classification applied in our material. Sec Biol Med Sci 2009;45-60. Crossref

11. Galli SJ. New concepts about the mast cell. New Engl J Med 1993;328:257-65. Crossref

12. Liu C, Crawford J M. The gastrointestinal tract. In: Kumar V, Abbas AK, Fausto N, eds. Robbins and Cotran: pathologic basis of diseases 7th edn. Philadelphia: Elsevier, 2005.813-816pp.

13. Ryan JJ, Morales JK, Falanga YT, Fernando JF,Macey MR. Mast cell regulation of the immune response. WAO Journal 2009;2:224-32. Crossref

14. Supajatura V, Ushio H, Wada A et al. Cutting edge: VacA, a vacuolating cytotoxin of Helicobacter pylori, directly activates mast cells for migration and production of proinflammatory cytokines. J Immunol 2002;168:2603-7. Crossref 